\title{
Removal of Adherent Ventricular Catheters
}

\author{
W.O. \\ William O. \\ Bell
}

Section on Neurosurgery, Department of Surgery, The Bowman Gray School of Medicine, Wake Forest University, Winston-Salem, N.C., USA William O. Bell, MD, Section on Neurosurgery, The Bowman Gray School of Medicine, Wake Forest University, 300 S Hawthorne Road, Winston-Salem, NC 27103 (USA)

Dear Sir,

I read with interest the recent article by Chambi and Hendrick [1]. Since 1985, I have been using a similar technique to remove adherent ventricular catheters after reading a similar report by Chehrazi and Duncan [2]. I have had no complications with its use in over 50 patients.

I believe this technique represents a useful adjunct in the avoidance of intraventricular bleeding during removal of catheters adhering to the choroid plexus.

References

Chambi I, Hendrick EB: A technique for removal of an adherent ventricular catheter. Pediatr Neurosci 1989;14:216-217.

Chehrazi B, Duncan CC: Removal of retained ventricular shunt catheter without craniotomy. Technical note. J Neurosurg 1982; 56:106-161. 